\title{
Application of a Palladium Hexacyanoferrate Film-Modified Aluminum Electrode to Electrocatalytic Oxidation of Hydrazine
}

\author{
Habib RazMi, ${ }^{\dagger}$ Azadeh Azadbakht, and Moayad Hossaini Sadr \\ Electrochemistry Research Lab., Faculty of Science, Azarbaijan University of Tarbiat Moallem P. O. Box: \\ 53714-161, Tabriz, Iran
}

\begin{abstract}
A palladium hexacyanoferrate (PdHCF) film as an electrocatalytic material was obtained at an aluminum (Al) electrode by a simple electroless dipping method. The modified $\mathrm{Al}$ electrode demonstrated a well-behaved redox couple due to the redox reaction of the PdHCF film. The PdHCF film showed an excellent electrocatalytic activity toward the oxidation of hydrazine. The electrocatalytic oxidation of hydrazine was studied by cyclic voltammetry and rotating disk electrode voltammetry techniques. A calibration graph obtained for the hydrazine consisted of two segments (localized at concentration ranges $0.39-10$ and $20-75 \mathrm{mM}$ ). The rate constant $k$ and transfer coefficient $\alpha$ for the catalytic reaction and the diffusion coefficient of hydrazine in the solution $D$, were found to be $3.11 \times 10^{3} \mathrm{M}^{-1} \mathrm{~s}^{-1}, 0.52$ and $8.03 \times 10^{-6} \mathrm{~cm}^{2}$ $\mathrm{s}^{-1}$ respectively. The modified electrode was used to amperometric determination of hydrazine in photographic developer. The interference of ascorbic acid and thiosulfate were investigated and greatly reduced using a thin film of Nafion on the modified electrode. The modified electrode indicated reproducible behavior and a high level of stability during electrochemical experiments, making it particularly suitable for analytical purposes.
\end{abstract}

(Received April 11, 2005; Accepted July 19, 2005)

\section{Introduction}

Hydrazine is used as an oxygen scavenger in industry and has been found to have wide applications as an antioxidant, a photographic developer, and an insecticide. ${ }^{1}$ It is also used as a fuel in fuel cells due to its high capacity and lack of contamination. $^{2}$ Because it is highly toxic and irritating, and is suspected of being carcinogenic and mutagenic, ${ }^{3}$ its detection has attracted considerable analytical interest.

Hydrazine can be determined by electrochemical methods because it is an electrochemically active compound. The voltammetric methods have been used for the determination of hydrazine. The mechanism and kinetics of hydrazine oxidation have been studied at several electrodes, including silver, nickel, ${ }^{5}$ gold $^{4}$ mercury ${ }^{4,6,7}$ and platinum. ${ }^{7-10}$ Unfortunately, the electrode process of hydrazine at conventional electrodes involved a large anodic overpotential, thus it is not a suitable analyte for these electrodes. One promising approach for minimizing overpotential effects is the use of an electrocatalytic process at chemically modified electrodes.

During the last decade, many efforts have been made to lower the oxidation potential of hydrazine in order to facilitate its voltammetric and amperometric detection at various chemically modified electrodes. For example, an electrochemically pretreated glassy carbon electrode, ${ }^{11}$ inorganic mixed-oxidation state Prussian blue $e^{12,13}$ and its analogues, ruthenium cyanide film-coated electrodes, ${ }^{14}$ carbon paste electrodes containing cobalt phtalocyanine, ${ }^{15,16}$ Nafion/ruthenium(III),${ }^{17}$ poly(4-vinyl)pyridine/palladium, ${ }^{18}$ cobalt tetraphenylporphyrin, ${ }^{19}$ cobalt protoporphyrin dimethyl ester, ${ }^{20}$ ultra-fine platinum and

$\dagger$ To whom correspondence should be addressed.

E-mail: h.razmi@azaruniv.edu ruthenium particles dispersed in porous carbon film ${ }^{21}$ or on carbon fiber electrodes, ${ }^{22}$ nickel ferricyanide, ${ }^{23}$ cobalt hexacyanoferrate ${ }^{24}$ modified glassy carbon electrodes have shown interesting catalytic properties toward the electrooxidation of hydrazine compounds. Also, recently, the electrooxidation of hydrazine has been studied at carbon ceramic electrodes modified with nickel hexacyanoferrate, ${ }^{25}$ carbon nanotube powder microelectrode, ${ }^{26}$ and cobalt pentacyanonitrosylferrate modified aluminum electrode. ${ }^{27}$

In the field of electrochemistry, some research activities have been oriented to develop new materials having electrocatalytic properties. $^{28-31}$ In most of these investigations the common substrates such as $\mathrm{Pt},{ }^{23} \mathrm{Au},{ }^{32} \mathrm{GC},{ }^{23}$ and $\mathrm{Ni}^{33}$ were utilized as matrices for the preparation of modified electrodes. In this regard we have recently developed a simple electroless procedure for the immobilization of nickel hexacyanoferrate (NiHCF) film on the $\mathrm{Al}$ surface. ${ }^{34}$ In addition, we have reported the electroless preparation and electrochemistry of nickel pentacyanonitrosylferrate (NiPCNF)-coated Al electrode. ${ }^{35}$ The NiPCNFIAl electrode was used for the electrooxidation of ascorbic acid,${ }^{36}$ thiosulfate, ${ }^{37}$ hydrazine, ${ }^{38}$ dopamine, ${ }^{39}$ and iodide. ${ }^{40}$

The electroless preparation of PdHCF film at the aluminum electrode was reported in the literature. ${ }^{41} \mathrm{We}$ used the PdHCFIAl electrode for the electrocatalytic oxidation of dopamine. ${ }^{42}$ To our knowledge, there are no reports on the catalytic oxidation of hydrazine at PdHCF-coated $\mathrm{Al}$ electrode. In order to extend the use of aluminum substrate, which is rarely exploited as an electrode substrate, we decided to investigate the oxidation of hydrazine at the PdHCFIAl electrode. The use of $\mathrm{Al}$ as an electrode matrix is interesting because of its simple preparation and modification. In addition, the application of an Al substrate instead of costly matrices such as Pt, $\mathrm{Au}$ and $\mathrm{Pd}$ would be appreciated with respect to economic problems in industrial electrochemistry and bio-electrochemistry. The 
present article describes the electrocatalytic effect of the PdHCF film and its application to the determination of hydrazine in the photographic developer. The stability of the modified electrode was investigated under various experimental conditions.

\section{Experimental}

\section{Chemicals and reagents}

A commercial aluminum bar with purity of $99.9 \pm 0.2 \%$ was used as substrate for the electrode matrix. Palladium chloride, potassium hexacyanoferrate, hydrazinium sulfate, potassium nitrate, sodium nitrate, and sodium dihydrogenphosphate were of analytical grade from Merck. The photographic developer solution was obtained from a local photographer's studio. Phosphate buffer solution was made up from $\mathrm{NaH}_{2} \mathrm{PO}_{4}$ and adjusted to desired $\mathrm{pH}$ by adding $1 \mathrm{M} \mathrm{NaOH}$ or $\mathrm{HNO}_{3}$ solution. All solutions were prepared with twice distilled water.

\section{Instrumentation}

The electrochemical experiments were carried out using VA Trace Analyzer Model 747 coupled with VA stand Model 746 from Metrohm. A conventional three-electrode cell was used at $25 \pm 1^{\circ} \mathrm{C}$. A silverlsilver chloride $(\mathrm{KCl} 3 \mathrm{M})$ electrode, a platinum wire and the aluminum disk electrode were used as reference, auxiliary and working electrodes, respectively.

\section{Fabrication of the modified electrode}

A cylindrical aluminum bar with $7 \mathrm{~mm}$ in diameter and 50 $\mathrm{mm}$ in length was used for the preparation of the rotating disk aluminum electrode as follows: The diameter of this bar was diminished to $3 \mathrm{~mm}$ at one side and then fitted into a Teflon rod of $7 \mathrm{~mm}$ in outer diameter and $20 \mathrm{~mm}$ in length. The other side of the aluminum bar was threaded by means of a suitable screw tap in order to connect it to an available rotating disk system. The aluminum disk electrode was used as working electrode. The Al surface was polished, firstly by a piece of medium emery sand paper (320-grit) and then by a piece of fine grade sand paper (1500-grit) to achieve a mirror-like surface. The polished $\mathrm{Al}$ surface was cleaned by dipping in $1 \mathrm{M} \mathrm{HNO}_{3}$ for about $1 \mathrm{~min}$ and then rinsed with twice-distilled water.

The preparation of PdHCF film was carried out in two different steps, including electroless deposition of metallic palladium on the $\mathrm{Al}$ surface and then derivatization of the metallic palladium to palladium hexacyanoferrate (PdHCF) film. The electroless deposition of metallic palladium was carried out by dipping the cleaned $\mathrm{Al}$ surface in $2 \mathrm{mM} \mathrm{PdCl}_{2}$ dissolved in $25 \%$ ammonia solution with formation of $\mathrm{Pd}\left(\mathrm{NH}_{3}\right)_{2} \mathrm{Cl}_{2}$ complex (plating solution). The thickness of metallic palladium deposited on the electrode surface depends on the immersion time of the electrode in the plating solution (in this work, the plating time varied from 5 to $10 \mathrm{~min}$ depending on the desired film thickness).

The Al electrode covered by metallic palladium was rinsed with doubly distilled water and then derivatized to PdHCF film by immersing it in freshly prepared $0.5 \mathrm{M} \mathrm{K}_{3}\left[\mathrm{Fe}(\mathrm{CN})_{6}\right]+0.5 \mathrm{M}$ $\mathrm{KNO}_{3}$ of $\mathrm{pH} 1-1.5$ adjusted with $\mathrm{HNO}_{3}$ (derivatizing solution). Indeed under these conditions the chemical transformation of the metallic palladium to PdHCF film occurred via a chemical oxidation reaction of metallic palladium to $\mathrm{Pd}^{2+}$ by $\mathrm{HNO}_{3}$ and a complexation reaction between $\mathrm{Pd}^{2+}$ and hexacyanoferrate anion at the electrode surface. As mentioned above, the thickness of the PdHCF film formed on the electrode can essentially be controlled through the plating step. However, the thickness of the film depends also on the immersion time of the electrode in
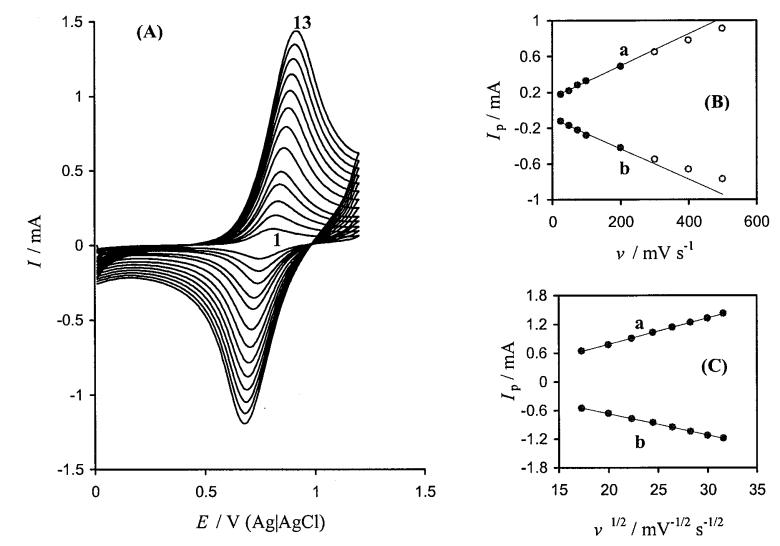

Fig. 1 (A) Cyclic voltammograms of the PdHCFIAl electrode recorded in $0.5 \mathrm{M} \mathrm{KNO}_{3}$ at different scan rates: 1 - 13) $25,50,75$, $100,200,300,400,500,600,700,800,900$, and $1000 \mathrm{mV} \mathrm{s}^{-1}$, respectively. (B) and (C) represent the variation of the anodic (a) and cathodic (b) peak current of the same electrode vs. potential scan rate and square root of potential scan rate, respectively.

the derivatizing solution (varied from 10 to $20 \mathrm{~min}$ ).

In order to achieve morphological stabilization of the crystal lattice of the film, we placed the freshly prepared electrode in $0.5 \mathrm{M} \mathrm{KNO}_{3}$ and cycled the voltage between 0.0 and $1.0 \mathrm{~V}$ versus $\mathrm{Ag} \mid \mathrm{AgCl}(\mathrm{KCl} 3 \mathrm{M})$ reference electrode for about 20 cycles with a scan rate of $50 \mathrm{mV} \mathrm{s}^{-1}$. The surface concentration of the mediator in the film per unit surface area of the electrode $(I)$ was determined from the area under the anodic peak of the cyclic voltammogram of the modified electrode recorded at a low scan rate.

\section{Determination of hydrazine in photographic developer}

The determination of hydrazine was carried out by a standard addition method using a Nafion-coated modified electrode. To do this, an accurate volume of photographic developer solution was transferred to a $10 \mathrm{~mL}$ voltammetric cell containing $10 \mathrm{~mL}$ phosphate buffer $(0.25 \mathrm{M} \mathrm{pH} 7)+0.5 \mathrm{M} \mathrm{KNO}_{3}$ and catalytic current was measured at fixed electrode potential $(0.95 \mathrm{~V})$ while the solution was stirred. Subsequently, the different volumes of standard hydrazine solution were added. The amount of hydrazine was calculated by the standard addition method.

\section{Results and Discussion}

\section{Electrochemistry of the modified electrode}

The representative cyclic voltammograms recorded in $0.5 \mathrm{M}$ $\mathrm{KNO}_{3}$ at a PdHCF-coated $\mathrm{Al}$ electrode are shown in Fig. 1A. The observation of reproducible and well-behaved cyclic voltammetric peaks provides evidence for the attachment of the PdHCF film with electrode surface. We observed that these peaks were not affected by stirring of the electrolyte or by the electrode, indicating that the material is bounded to the electrode surface. The formal potential $E^{\circ \prime}=\left(E_{\mathrm{pa}}+E_{\mathrm{pc}}\right) / 2$ is $0.78 \mathrm{~V}$ with peak potential separation of $44 \mathrm{mV}$ for scan rate of $25 \mathrm{mV} \mathrm{s}^{-1}$. Since the $\mathrm{Pd}^{+2}$ cations in the modifying film are practically non-electroactive in the potential range examined, 0 $-1.2 \mathrm{~V}$, the redox peaks present a single electron process of hexacyanoferrate(III/II) in the film. The bare Al electrode, unlike the PdHCFIAl modified electrode, shows no redox peak in the same supporting electrolyte. 


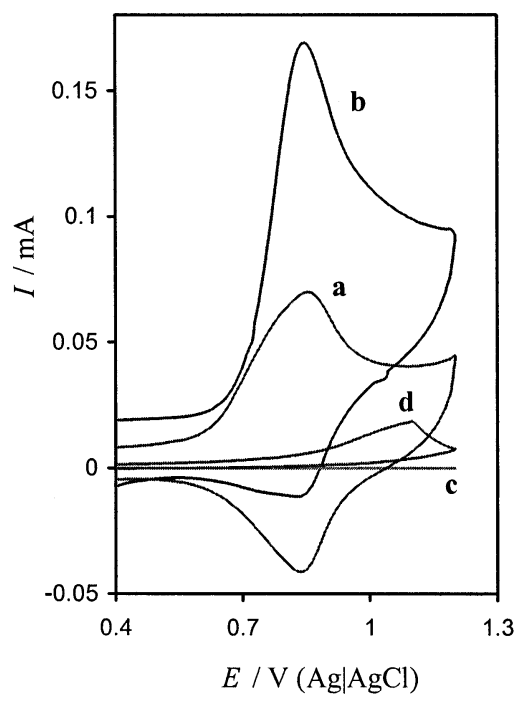

Fig. 2 Cyclic voltammograms recorded at the PdHCFIAl electrode $(\mathrm{a}, \mathrm{b})$ and bare $\mathrm{Al}$ electrode $(\mathrm{c}, \mathrm{d})$ in the absence $(\mathrm{a}, \mathrm{c})$ and presence $(\mathrm{b}, \mathrm{d})$ of $3.9 \mathrm{mM}$ hydrazine at a scan rate of $100 \mathrm{mV} \mathrm{s}^{-1}$. The supporting electrolyte was phosphate buffer $(0.25 \mathrm{M} \mathrm{pH} 7)+0.5 \mathrm{M}$ $\mathrm{KNO}_{3}$.

The peak currents obtained at the PdHCFIAl modified electrode are linearly proportional to the scan rate in the range $25-200 \mathrm{mV} \mathrm{s}^{-1}$ (Fig. 1B). The $I_{\mathrm{pa}} / I_{\mathrm{pc}}$ ratio remains almost equal to unity, as expected for a surface-type behavior. The variations of peak separation $\Delta E_{\mathrm{p}}$, are not small for scan rates in the range from 25 to $75 \mathrm{mV} \mathrm{s}^{-1}(51 \mathrm{mV})$. This deviation of redox process from the ideal surface redox behavior appeared even at low scan rates; this may be attributed to the limitations associated with charge propagation in the film, some chemical interaction between the ions and the modified film, the polarizability of the cation influencing its penetration in or out of the PdHCF film, or non-equivalent sites in the PdHCF film. At higher scan rates (>300 $\mathrm{mV} \mathrm{s}^{-1}$ ), a wider splitting appears, indicating the limitation arising from the cation diffusion and charge transfer kinetics in the film. The anodic and cathodic peak currents are linearly proportional to the square root of scan rate (Fig. 1C), which is expected for diffusion-controlled electrode processes.

\section{Electrocatalytic oxidation of hydrazine}

The cyclic voltammograms recorded at the bare and PdHCFcoated $\mathrm{Al}$ electrodes in the absence and presence of hydrazine are shown for comparison in Fig. 2. As can be seen in the figure, hydrazine is electro-inactive at the bare $\mathrm{Al}$ electrode in this electrolyte solution (curve d). The PdHCF-modified Al electrode in the blank solution exhibits a well-behaved redox reaction (curve a). Upon the addition of $3.9 \mathrm{mM}$ hydrazine, an enhancement in the anodic peak current is observed and the cathodic peak current decreased (curve b). This behavior is typical for mediated oxidation

Figure 3 shows well-behaved cyclic voltammograms recorded at a PdHCF-modified electrode in the presence of different concentrations of hydrazine. This figure demonstrates a typical catalytic enhancement of the hydrazine oxidation current and a corresponding loss of the mediator reduction peak. The anodic peak current increases with hydrazine concentration in the solution. A typical calibration curve based on the variation of anodic peak current (inset to Fig. 3) shows clearly that the plot of $I_{\mathrm{p}}$ versus hydrazine concentration between 0.39 and $75 \mathrm{mM}$,

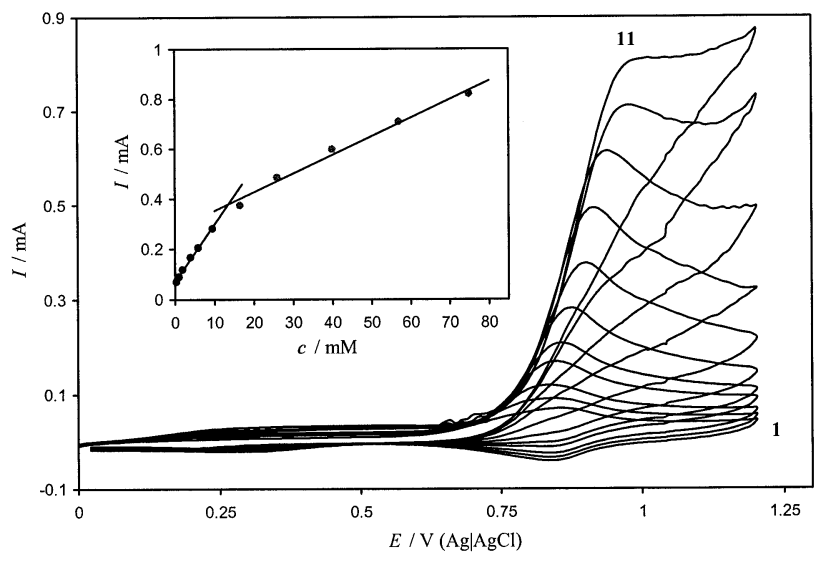

Fig. 3 Cyclic voltammograms recorded at the PdHCFIAl electrode in the presence of different hydrazine concentrations: 1-11) 0.39 , $0.99,1.9,3.9,5.8,9.5,16.5,26,40,57$, and $75 \mathrm{mM}$ respectively. Potential scan rates, $100 \mathrm{mV} \mathrm{s}^{-1}$. The supporting electrolyte was as in Fig. 2. The inset shows the plot of anodic peak current versus concentration of hydrazine
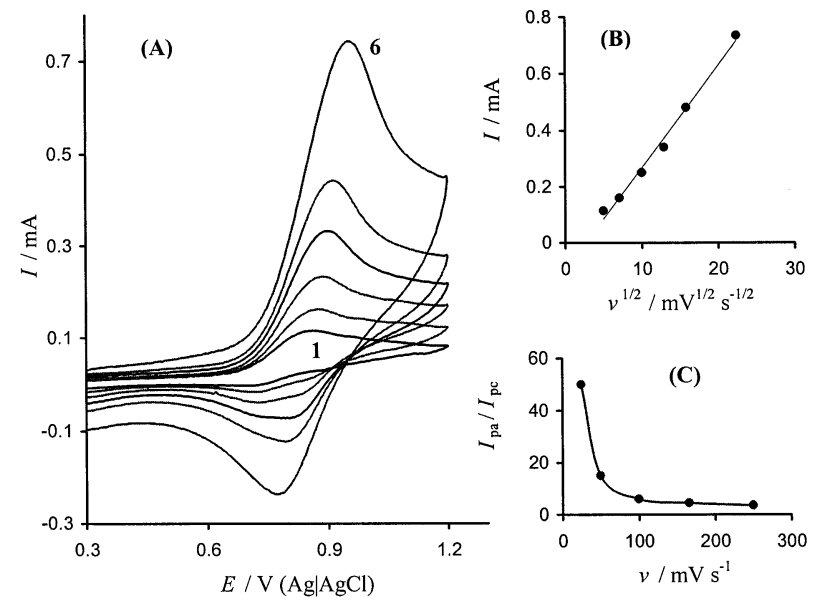

Fig. 4 (A) Cyclic voltammograms of the PdHCFIAl electrode in the presence of $8.7 \mathrm{mM}$ hydrazine at various potential scan rates: $1-6$ ) $25,50,75,100,167$ and $250 \mathrm{mV} \mathrm{s}^{-1}$, respectively. The supporting electrolyte was as in Fig. 2. (B) The variation of anodic peak current, $I_{\mathrm{pa}} v s$. square root of potential scan rate, $\mathrm{v}^{1 / 2}$. (C) The variation of anodic and cathodic peak current ratio $\left(I_{\mathrm{pa}} / I_{\mathrm{pc}}\right) v s$. potential scan rate.

consists of two linear segments with different slopes, corresponding to two different ranges of hydrazine concentration. We ascribe this to a change in catalytic reaction conditions arising from the formation of nitrogen gas bubbles at the surface of the film as has already been reported by others. ${ }^{43}$ Indeed, at low concentrations of hydrazine, the gas formed is negligible and thus has no effect on the diffusion of hydrazine toward the electrode surface (gas evolution unaffected zone). At high concentrations of hydrazine, however, gas evolution at the electrode surface reduces to some extent the normal diffusion of the substrate (gas evolution affected zone).

Figure 4A shows the cyclic voltammograms recorded at a PdHCF-coated Al electrode for various scan rates (25 to 250 $\mathrm{mV} \mathrm{s}^{-1}$ ) in the presence of $8.7 \mathrm{mM}$ hydrazine. As can be seen, the excellent catalytic effect of the PdHCF film appeared at scan rates up to $100 \mathrm{mV} \mathrm{s}^{-1}$ owing to a considerable catalytic reaction rate. The oxidation peak current increases linearly with the square root of the scan rate (Fig. 4B), suggesting that the 

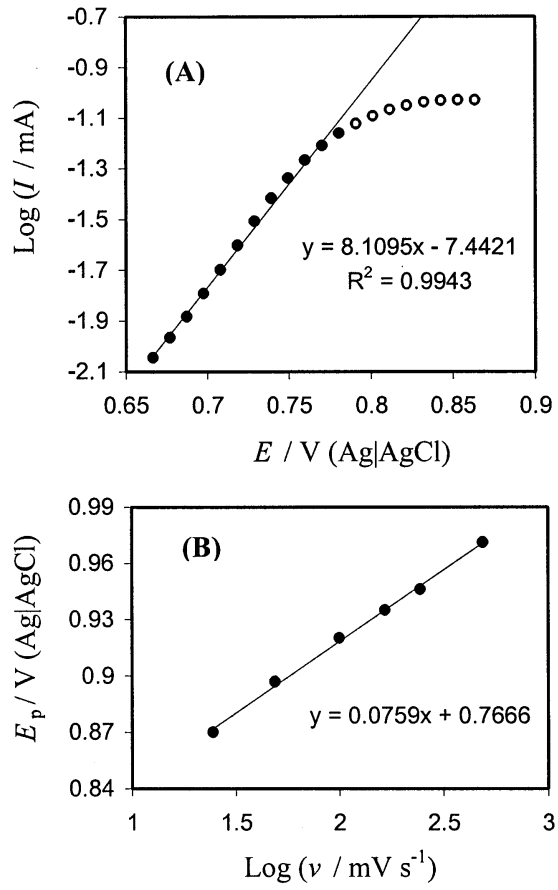

Fig. 5 (A) A Tafel-like plot derived from current-potential curve obtained on the PdHCFIAl electrode in the presence of $8.7 \mathrm{mM}$ hydrazine at scan rate of $10 \mathrm{mV} \mathrm{s}{ }^{-1}$. (B) The dependence of the anodic peak potential $E_{\mathrm{pa}} v s . \log v$ derived from the voltammograms shown in Fig. 4A. The supporting electrolyte was as in Fig. 2.

reaction is mass transfer-controlled. Moreover, the variation of anodic and cathodic peak ratio $\left(I_{\mathrm{pa}} / I_{\mathrm{pc}}\right)$ versus scan rate (Fig. $\left.4 \mathrm{C}\right)$, exhibits a shape typical of an EC catalytic process. However, according to the cyclic voltammograms (Fig. 4A) the peak potential and thus the over-potential for the catalytic oxidation of hydrazine is increased with increasing scan rate, suggesting a kinetic limitation in the reaction between the redox sites of the PdHCF film and hydrazine. We, therefore, concluded that the overall electrochemical reaction might be mixed-controlled by mass transport and by charge transfer kinetics.

In order to obtain some information on the rate determining step, we drew a Tafel-like plot (Fig. 5A) using the data from the rising part of the current-voltage curve recorded at a low scan rate of $10 \mathrm{mV} \mathrm{s}^{-1}$, for $8.7 \mathrm{mM}$ hydrazine. The linearity of $\log I$ versus $E$ plot at the potential range $0.65-0.75 \mathrm{~V}$, implies the intervention of the kinetics of the electrode process. The slope of this plot can be used to estimate the number of electrons transferred in the rate-determining step. According to Fig. 5A, the Tafel slope $(b)$ for the linear part of the plot was estimated to

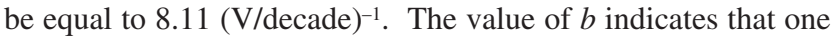
electron transfer process is the rate-limiting step, assuming a transfer coefficient $(\alpha)$ of about 0.52 . The Tafel slope $b$, can be obtained by another approach using the following equation that is valid for a totally irreversible diffusion-controlled process: ${ }^{44}$

$$
E_{\mathrm{p}}=(b / 2) \log v+\mathrm{constant}
$$

On the basis of Eq. (1), the slope of $E_{\mathrm{p}}$ versus $\log v$ plot is $b / 2$, where $b$ indicates the Tafel slope. The plot of $E_{\mathrm{p}}$ versus $\log v$ indicates a linear variation for scan rates ranging from 25 to 250 $\mathrm{mV} \mathrm{s}^{-1}$ (Fig. 5B). The slope is $\partial E_{\mathrm{p}} / \partial \log v$, which was found to be $0.1165 \mathrm{~V}$ in this work. So, $b=2 \times 0.0759=0.1518 \mathrm{~V}$. Assuming that the number of electrons transferred in the ratelimiting step is equal to 1 , a transfer coefficient of $\alpha$ was estimated as 0.61 . If we assumed $n=2, \alpha$ would then be equal to 0.805 , which is not a common value, because for most electrode processes $\alpha$ ranges between 0.75 and $0.25 .{ }^{45}$ The results obtained from the two different methods are in good agreement. These results obtained from cyclic voltammetry lead to the conclusion that the overall electrochemical oxidation of hydrazine under these conditions might be mixed-controlled by transportation of hydrazine in the solution and by a crossexchange process between hydrazine and the redox sites of the PdHCF film. Under solution conditions, where hydrazine is present in its protonated form ( $\mathrm{p} K_{\mathrm{a}}$ of hydrazine is 7.9$)$, the process according to an EC catalytic mechanism can be expressed as:

$$
\begin{aligned}
\mathrm{K}_{2} \mathrm{Pd}^{\mathrm{II}}\left[\mathrm{Fe}^{\mathrm{II}}(\mathrm{CN})_{6}\right] \longrightarrow & \mathrm{KPd}^{\mathrm{II}}\left[\mathrm{Fe}^{\mathrm{III}}(\mathrm{CN})_{6}\right]+\mathrm{K}^{+}+\mathrm{e}^{-} \\
\mathrm{KPd}^{\mathrm{II}}\left[\mathrm{Fe}^{\mathrm{III}}(\mathrm{CN})_{6}\right]+ & \mathrm{K}^{+}+\mathrm{N}_{2} \mathrm{H}_{5}{ }^{+} \longrightarrow \\
& \mathrm{K}_{2} \mathrm{Pd}^{\mathrm{II}}\left[\mathrm{Fe}^{\mathrm{II}}(\mathrm{CN})_{6}\right]+\mathrm{N}_{2} \mathrm{H}_{3}+2 \mathrm{H}^{+} \\
3 \mathrm{KPd}^{\mathrm{II}}\left[\mathrm{Fe}^{\mathrm{III}}(\mathrm{CN})_{6}\right]+ & 3 \mathrm{~K}^{+}+\mathrm{N}_{2} \mathrm{H}_{3} \longrightarrow \\
& 3 \mathrm{~K}_{2} \mathrm{Pd}^{\mathrm{II}}\left[\mathrm{Fe}^{\mathrm{II}}(\mathrm{CN})_{6}\right]+\mathrm{N}_{2}+3 \mathrm{H}^{+}
\end{aligned}
$$

The symbols E and C imply the electrochemical and chemical reactions. The overall chemical reaction is shown as follows:

$$
\begin{aligned}
4 \mathrm{KPd}^{\mathrm{II}}\left[\mathrm{Fe}^{\mathrm{III}}(\mathrm{CN})_{6}\right]+ & 4 \mathrm{~K}^{+}+\mathrm{N}_{2} \mathrm{H}_{5}+\longrightarrow \\
& 4 \mathrm{~K}_{2} \mathrm{Pd}^{\mathrm{II}}\left[\mathrm{Fe}^{\mathrm{II}}(\mathrm{CN})_{6}\right]+\mathrm{N}_{2}+5 \mathrm{H}^{+}
\end{aligned}
$$

The value of catalytic reaction rate constant $k$ (reaction $\mathrm{C}_{1}$ ) can be evaluated by cyclic voltammetry. Andrieux and Saveant ${ }^{46}$ developed a theoretical model for a catalytic mechanism. In redox catalysis, the catalyst couple is involved in an outer sphere electron transfer reaction with the substrate, simply playing the role of an electron carrier between the electrode and the substrate. Andrieux and Saveant found that, for small values of the kinetic parameter (large $v$, small $k$ and $\Gamma$ ), an S-shaped wave independent of sweep rate is obtained:

$$
\begin{aligned}
& I_{\mathrm{c}}=\left(k \Gamma F S c_{\mathrm{o}}\right) /[1+\exp (-\xi)] \\
& \xi=-(F / R T)\left(E-E^{\circ}\right) \Gamma
\end{aligned}
$$

with its half-wave potential located at $E^{\mathrm{o}}$ of the catalyst. Here $I_{\mathrm{c}}, k, \Gamma, F, S$ and $c_{\mathrm{o}}$ present the catalytic current, catalytic rate constant, catalyst surface concentration, faraday constant, electrode surface area, and substrate concentration in the solution, respectively. For large kinetic parameters (small $v$, large $k$ and $\Gamma$ ) a peaked-shaped wave proportional to $v^{1 / 2}$ is found with:

$$
I_{\mathrm{p}}=0.496 n F s c_{\mathrm{o}} D^{1 / 2}(F v / R T)^{1 / 2}
$$

The low values of $k$ result in a value of the coefficient lower than 0.496. For low scan rate $\left(25 \mathrm{mV} \mathrm{s}^{-1}\right)$, a hydrazine concentration of $26 \mathrm{mM}$ and a surface coverage of $2.4 \times 10^{-8}$ mol cm$~^{-2}$, the average value of this constant was found to be 0.459. Based on approach developed by Andrieux and Saveant, using Fig. 1a in Ref. 46, we calculated a mean value of $2.8 \times 10^{3}$ $\mathrm{M}^{-1} \mathrm{~s}^{-1}$ for $k$.

\section{Rotating disk electrode (RDE) voltammetry}

The electrocatalytic activity of the PdHCF film-modified Al electrode toward the oxidation of hydrazine was also evaluated using RDE voltammetry technique. The steady state $I-E$ curves 
were recorded for the oxidation of hydrazine at a PdHCF filmmodified rotating $\mathrm{Al}$ disk electrode. Typical examples of the $I-E$ curves (RDE voltammograms) for hydrazine concentration of $2.8 \mathrm{mM}$ at the PdHCFIAl modified electrode (curves 1-6) have been presented in Fig. 6A. The limiting current obtained on the modified electrode increases with the rotation speed of the electrode. The linearity of the Levich plots at lower rotation rates indicates that the limiting current is mass-transport controlled (Fig. 6B). The Levich plots deviated from linearity at higher rotation rates, suggesting a kinetic limitation. Under these conditions, the Koutecky-Levich equation ${ }^{47}$ can be used to determine the rate constant. The limiting current is given by Eq. (5):

$$
\frac{1}{I_{\mathrm{lim}}}=\frac{1}{I_{\mathrm{lev}}}+\frac{1}{I_{\mathrm{K}}}
$$

Here $I_{\mathrm{lev}}$ is the Levich current and $I_{\mathrm{K}}$ is the kinetic current. $I_{\mathrm{lev}}$ and $I_{\mathrm{K}}$ are defined by Eqs. (6) and (7):

$$
I_{\mathrm{lev}}=0.62 n F A D^{2 / 3} v^{-1 / 6} \omega^{1 / 2} c_{\mathrm{o}}
$$

Here $n$ is the number of electrons, $D$ is the diffusion coefficient of the substrate (hydrazine), $F$ is the faradaic constant, $c_{\mathrm{o}}$ is the bulk concentration of the substrate (hydrazine), $A$ is the electrode area, $v$ is the kinematic viscosity of the solution and $\omega$ is the rotation rate.

$$
I_{\mathrm{K}}=n F A c_{\mathrm{o}} k \Gamma
$$

Here $k$ is the rate constant $\left(\mathrm{dm}^{3} \mathrm{~mol}^{-1} \mathrm{~s}^{-1}\right)$ governing the reaction of the catalyst with hydrazine, and $\Gamma$ is the quantity of the catalyst on the electrode surface $\left(\mathrm{mol} \mathrm{cm}{ }^{-2}\right)$.

In the case of a mass transfer-controlled electrochemical reaction, the relationship between the limiting current and the rotating speed should obey the Levich equation (Eq. (6)). Based on Eq. (6), the plot of the limiting current as function of the $\omega^{1 / 2}$ should be a straight line. This occurred for the low rotation speed of electrode and corresponds for the initial part of Levich plots. The diffusion coefficient of hydrazine in the solution $D$ can be obtained from the slope of the Levich plot. The value of $D$ in this medium was found to be $2.98 \times 10^{-6} \mathrm{~cm}^{2} \mathrm{~s}^{-1}$. This result is slightly lower than that reported in some references. ${ }^{38,43}$ According to the Levich plots (Fig. 6B), the current increases with increasing electrode rotation speed, but was found to be non-linear, indicating kinetic limitations. In this case, the catalytic current $I_{\text {cat }}$ related to the mediated reaction is a function of both Levich current $I_{\mathrm{lev}}$, and kinetic current $I_{\mathrm{K}}$. Therefore, mass transfer of hydrazine in the solution and the electron crossexchange between hydrazine and the PdHCF redox sites become dominant, and the Koutecky-Levich equation may be used.

According to Eg. (5), the plot of $I^{-1}$ versus $\omega^{-1 / 2}$ gives a straight line (as shown in Fig. 6C). The value of the rate constant for the catalytic reaction $k$, can be obtained from the intercept of the Koutecky-Levich plot. The value of $k$ was found to be in the range $3.09 \times 10^{3}$ to $3.14 \times 10^{3} \mathrm{M}^{-1} \mathrm{~s}^{-1}$ for hydrazine concentration in the range $2.8-3.3 \mathrm{mM}$, using $\Gamma=$ $9.02 \times 10^{-9} \mathrm{~mol} \mathrm{~cm}^{-2}$. The value of $k$ is in good agreement with that obtained by cyclic voltammetry. The diffusion coefficient of hydrazine, $D$ may be obtained from the slope of Koutecky-Levich plots. The mean value of $D$ was found to be $8.03 \times 10^{-6} \mathrm{~cm}^{2} \mathrm{~s}^{-1}$, which is in agreement with that reported in the references. ${ }^{38,43}$ But the values of $D$ obtained from the Levich plot was smaller than those obtained from Koutecky-Levich
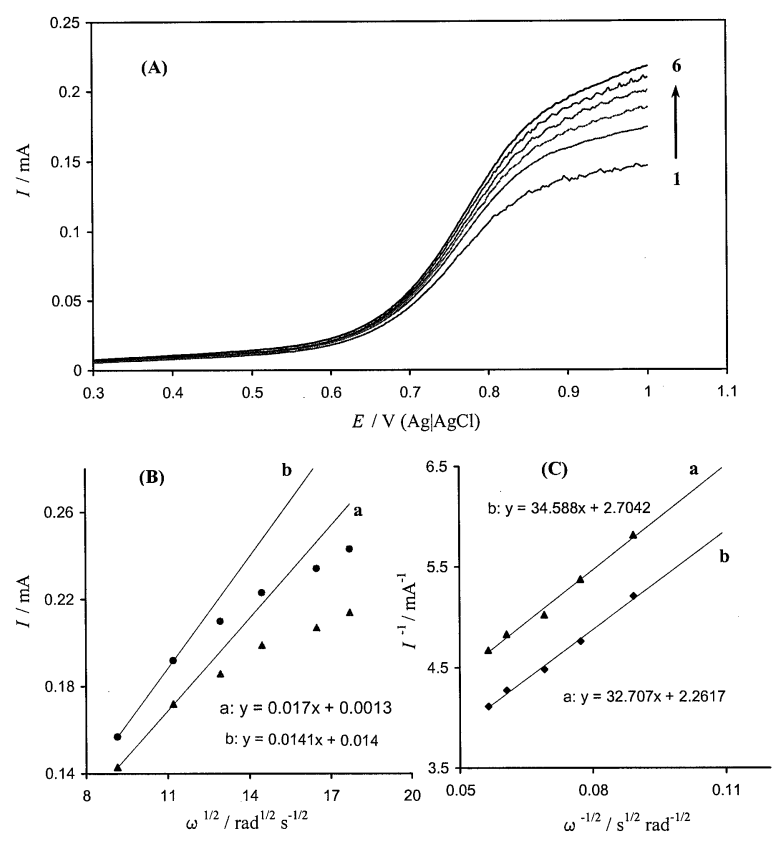

Fig. 6 Rotating disk electrode voltammograms recorded at the $\mathrm{PdHCF} \mid \mathrm{Al}$ electrode for $2.8 \mathrm{mM}$ hydrazine. The rotation rates are in rpm: 1 -6) 800, 1200, 1600, 2000, 2600, and 3000 respectively. Potential sweep rate, $20 \mathrm{mV} \mathrm{s}^{-1}$. The supporting electrolyte was as in Fig. 2. $\Gamma=9.02 \times 10^{-9} \mathrm{~mol} \mathrm{~cm}^{-2}$. Insets (A) and (B) represent Levich and Koutecky-Levich plots (respectively) for various concentrations of hydrazine: (a) 2.8 and (b) $3.3 \mathrm{mM}$.

plots. This discrepancy may be attributed to the interference of kinetics of the electron cross-exchange process between hydrazine and redox sites of the PdHCF film on the Levich plots even at the low rotation speeds of the electrode.

\section{Interference study}

Generally, both ascorbic acid (AA) and hydrazine are used as antioxidants and can be oxidized electrochemically at a similar potential. Thus, AA may be a major interferent in the determination of hydrazine. In order to reduce the interference of AA, a Nafion-coated PdHCFIAl electrode was prepared. Nafion film is a cation exchange polymer and repels ascorbic acid (AA) and other negatively charged species at optimized conditions. Nafion film can provide a transport channel only for the cations.

Figure 7 shows the cyclic voltammograms recorded at the PdHCFIAl electrode (A) and Nafion-coated PdHCFlAl electrode (B), in the absence of AA and hydrazine (curves a in all figures) and in the presence of $20 \mathrm{mM}$ AA (curves $b$ in all figures) and $20 \mathrm{mM}$ hydrazine (curves $\mathrm{c}$ in all figures). All voltammograms were recorded in phosphate buffer $(0.25 \mathrm{M}, \mathrm{pH} 7)+0.5 \mathrm{M}$ $\mathrm{KNO}_{3}$ solution. As can be seen, the elctrocatalytic activity of the PdHCF-modified $\mathrm{Al}$ electrode toward oxidation of hydrazine remains almost unchanged in the presence of Nafion film. Vice versa, the oxidation response of the ascorbic acid at Nafion-coated PdHCFIAl electrode completely disappeared. Therefore, a Nafion-coated PdHCFIAl electrode may be used for the selective determination of hydrazine in the presence of AA.

A series of experiments were done in solutions of thiosulfate using the modified electrode without and with Nafion film (figures not shown). The results showed that the Nafion film repels thiosulfate species due to its negative charge. The 

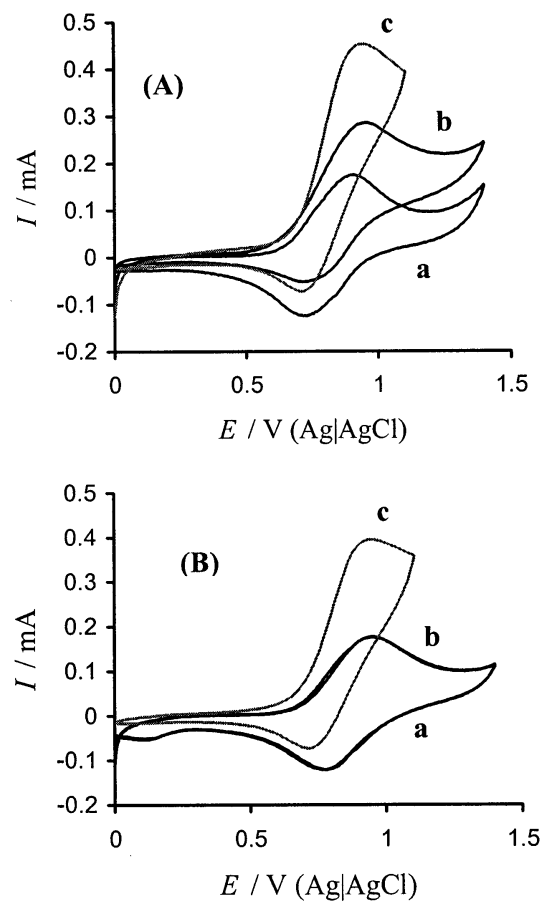

Fig. 7 Cyclic voltammograms recorded at a PdHCFIAl electrode (A) and Nafion-coated PdHCF|Al electrode (B), in the absence of AA and hydrazine (curves a in all figures) and in the presence of $20 \mathrm{mM}$ AA (curves b in all figures) and $20 \mathrm{mM}$ hydrazine (curves $\mathrm{c}$ in al figures). Potential sweep rate, $50 \mathrm{mV} \mathrm{s}^{-1}$. The supporting electrolyte was as in Fig. 2.

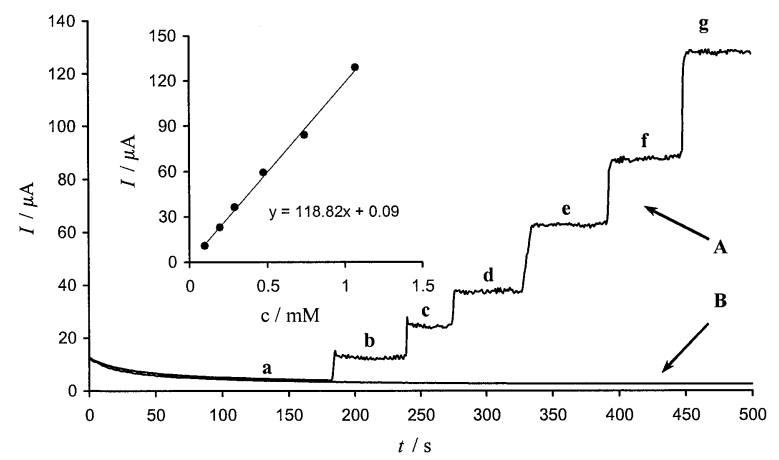

Fig. 8 (A) Amperogram showing the current response of the modified electrode for different volumes of $0.1 \mathrm{M}$ standard solution of hydrazine added to $10 \mathrm{~mL}$ of supporting electrolyte as in Fig. 2: a, zero; b, a + 0.1; c, b + 0.1; d, c + 0.1; e, d + 0.2; f, d + 0.3; g, f + 0.4 $\mathrm{mL}$. (B) Amperogram showing the current response of the same modified electrode in supporting electrolyte of $0.5 \mathrm{M} \mathrm{KNO}_{3}$. The inset shows the calibration curve obtained from amperogram A with base-line correction.

electrochemical response of the Nafion-coated modified electrode in solution of both hydrazine and thiosulfate was nearly independent of thiosulfate concentration. This shows that the Nafion films can provide a transport channel only for the cationic hydrazine species $\left(\mathrm{N}_{2} \mathrm{H}_{5}^{+}, \mathrm{pH} 7\right)$.

According to the authors, in order to determine hydrazine in complex matrices containing different interfering species, the chromatographic methods must be used. The chromatographic separation and electrochemical detection is a powerful technique for separate analytical responses of substrates which

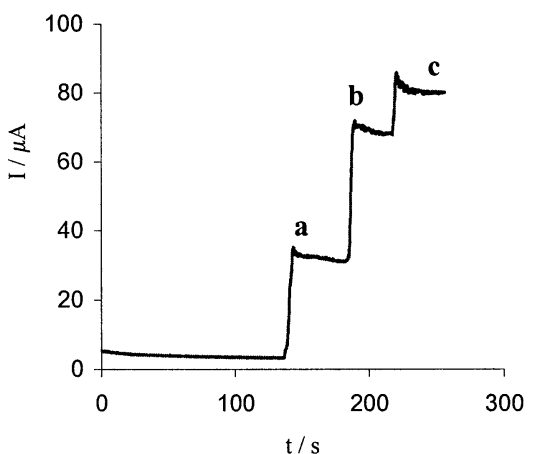

Fig. 9 Amperogram showing the current response of the modified electrode for $0.6 \mathrm{~mL}$ photographic developer (step a), and $0.5 \mathrm{~mL}$ and $0.1 \mathrm{~mL}$ volumes of $0.1 \mathrm{M}$ standard hydrazine solution to added 10 $\mathrm{mL}$ supporting electrolyte, as in Fig. 2.

are oxidized at the same potential.

\section{Hydrodynamic amperometry}

When the cyclic voltammetry and hydrodynamic voltammetry are utilized as analytical methods using modified electrodes, the former method has a relatively high detection limit. ${ }^{48}$ In order to enhance the sensitivity of the method (lowering the detection limit), one can use hydrodynamic amperometric measurement at a fixed potential of $0.95 \mathrm{~V}$. Another advantage of this method is an easy base-line correction of catalytic current. Typical hydrodynamic amperograms obtained by successively addition of $0.1 \mathrm{M}$ standard hydrazine solution to $10 \mathrm{~mL}$ phosphate buffer solution ( $\mathrm{pH} 7)$ are shown in Fig. 8. The inset to Fig. 8 shows that the catalytic current is linearly increased after addition of different increments of standard hydrazine solution. The detection limit was found to be $4.6 \times 10^{-6} \mathrm{M}$

\section{Analytical applications}

Since the present amperometric method is very sensitive, and a small volume of the sample is adequate for the hydrazine determination, the standard addition method is suitable for simple and rapid evaluation of hydrazine. Figure 9 shows the amperogram recorded at the modified electrode during addition of photographic developer (step a) and hydrazine standard solutions (steps b, c). The reliability of the amperometric determination of hydrazine in photographic developer was verified using an iodimetric procedure described in the literature. ${ }^{49}$ For this purpose, a $0.05 \mathrm{M}$ iodine solution which was standardized in the usual way with a primary standard of $\mathrm{As}_{2} \mathrm{O}_{3}$ or titrisol thiosulfate solution was used. The results of statistical calculation shown in Table 1 indicate a good precision and good agreement between the repeatability of the proposed and official methods ( $F$-test) and the mean values obtained ( $t$-test)

\section{Stability of the modified electrode}

The stability of the PdHCFIAl modified electrode was investigated by cyclic voltammetry. The peak current of the mediator was considered as a factor indicating the stability of modified electrode at various conditions of operation. The peak current of the modified electrode was very slightly decreased when it was stored in air for several months ( $\sim 3 \%$ per month). The modified electrode showed a good stability in hydrazine solutions. 
Table 1 Determination of hydrazine in photographic developer

\begin{tabular}{ccccc}
\hline No. & Found $/ M$ & RSD, \% & Found $/ M$ & RSD, \% \\
\hline 1 & 0.045 & & 0.042 & \\
2 & 0.043 & & 0.041 & \\
3 & 0.042 & \multirow{2}{*}{5.4} & 0.039 & \multirow{2}{*}{3.6} \\
4 & 0.039 & & 0.042 & \\
5 & 0.044 & & 0.043 & \\
Average & 0.0426 & & 0.0414 & \\
\hline
\end{tabular}

a. By amperometric method.

b. By iodimetric titration method.

\section{Conclusion}

The aluminum surface coated with PdHCF film can catalyze the oxidation of hydrazine via surface-layer mediated charge transfer. The charge-transfer step of the rate-limiting reaction is found to be a one-electron abstraction step; however, the final product obtained is nitrogen gas. The currents obtained in cyclic voltammetry and steady-state hydrodynamic voltammetry are diffusion-controlled for low concentrations of hydrazine, while at higher hydrazine concentrations the slopes of the currents versus the hydrazine concentration are decreased significantly, most probably because of nitrogen gas evolution. The rate constants for the electrocatalytic reaction obtained by different approaches are in good agreement. The modified aluminum electrode prepared is stable for several months, which makes it useful for electrocatalytic determination of hydrazine. The modified electrode was used for amperometric determination of hydrazine in photographic developer and the satisfactory results were obtained.

\section{References}

1. S. Amlathe and V. K. Gupta, Analyst, 1988, 113, 1481.

2. Z. Zhu, J. Ren, and Z. Quing, Gaoden Xиexiao Huaxue Хиеbao, 1992, 14, 1710.

3. E. H. Vernot, J. D. MacEwen, and R. H. Bruner, Fundamen. Appl. Toxicol., 1985, 5, 1050.

4. K. Korinek, J. Korita, and M. Nusiloua, J. Electroanal. Chem., 1969, 21, 421.

5. M. Felischmann, K. Korinek, and D. Plrtcher, J. Electroanal. Chem., 1972, 34, 499.

6. U. Eissner and E. Gileadi, J. Electroanal. Chem., 1970, 28, 81.

7. J. A. Harrison and Z. A. Khan, J. Electroanal. Chem., 1970, 26, 1 .

8. M. Perek and S. Bruckenstein, J. Electroanal. Chem., 1973, 47, 329.

9. A. J. Bard, Anal. Chem., 1963, 35, 1603.

10. J. A. Harrison and Z. A. Khan, J. Electroanal. Chem., 1970, $28,131$.

11. K. Ravichandran and R. P. Baldwin, Anal. Chem., 1983, 55, 1782.

12. W. Y. Hou and E. Wang, Anal. Chim. Acta, 1992, 257, 275.

13. U. Scharf and E. W. Grabner, Electrochim. Acta, 1996, 41, 233.

14. J. Wang and Z. Lu, Electroanalysis, 1982, 1, 517.

15. K. M. Korfhage, K. Ravichandran, and R. P. Baldwin, Anal. Chem., 1984, 56, 1514.

16. X. Li, S. Zhang, and C. Sun, J. Electroanal. Chem., 2003,
$553,139$.

17. I. G. Casella, M. R. Guascito, A. M. Salvi, and E. Desimoni, Anal. Chim. Acta, 1997, 354, 333.

18. T. Li and E. Wang, Electroanalysis, 1997, 9, 1205.

19. W. Hou, J. Hua, and E. Wang, Chin. Sci. Bull., 1991, 36, 785.

20. G. Kokkinidis and P. D. Jannakoudakis, J. Electroanal. Chem., 1981, 130, 153.

21. J. Wang, P. V. A. Pamidi, C. L. Renschler, and C. White, J. Electroanal. Chem., 1996, 404, 137.

22. W. H. Zhou, L. Xu, M. J. Wu, L. J. Xu, and E. Wang, Anal. Chim. Acta, 1994, 299, 189.

23. C. Lin and A. B. Bocarsly, J. Electroanal. Chem., 1991, 300,325 .

24. S. M. Golabi and F. Noor-Mohammadi, J. Solid State Electrochem., 1998, 2, 30.

25. A. Salimi and K. Abdi, Talanta, 2004, 63, 475.

26. Y.-D. Zhao, W.-D. Zhang, H. Chen, and Q.-M. Luo, Talanta, 2002, 58, 529.

27. M. H. Pournaghi-Azar and R. Sabzi, J. Electroanal. Chem., 2003, 543, 115

28. F. Y. Bernadette, Y. Hin, and C. R. Lowe, Anal. Chem., 1987, 59, 2111

29. C.-X. Cai, K.-H. Xue, and S.-M. Xu, J. Electroanal. Chem., 2000, 486, 111.

30. J. A. Cox and P. J. Kulesza, Anal. Chem., 1984, 56, 1021.

31. S.-M. Chen and K.-T. Peng, J. Electroanal. Chem., 2003, $547,179$.

32. C. Cai, H. Ju, and H. Chen, Anal. Chim. Acta, 1995, 310, 145.

33. C. Cai, H. Ju, and H. Chen, Anal. Chim. Acta, 1995, 397, 185.

34. M. H. Pournaghi-Azar and H. Razmi-Nerbin, $J$. Electroanal. Chem., 1998, 456, 83.

35. M. H. Pournaghi-Azar and H. Razmi-Nerbin, Electroanalysis, 2000, 12, 209.

36. M. H. Pournaghi-Azar and H. Razmi-Nerbin, $J$. Electroanal. Chem., 2000, 488, 17.

37. M. H. Pournaghi-Azar and H. Razmi-Nerbin, Electroanalysis, 2001, 13, 465.

38. H. Razmi-Nerbin and M. H. Pournaghi-Azar, J. Solid State Electrochem., 2002, 6, 126.

39. H. Razmi, M. Agazadeh, and B. Habibi, J. Electroanal. Chem., 2003, 547, 25.

40. H. Razmi, M. Hossaini Sadr, and B. Habibi-A, J. Electroanal. Chem., 2005, 574, 207.

41. M. H. Pournaghi-Azar and H. Dastangoo, J. Electroanal. Chem., 2002, 523, 26.

42. H. Razmi and A. Azadbakht, Electrochim. Acta, 2005, 50, 2193.

43. S. M. Golabi, H. R. Zare, and M. Hamzehloo, Microchem J., 2001, 69, 111.

44. J. A. Harrison and Z. A. Khan, J. Electroanal. Chem., 1970, 28, 153.

45. A. J. Bard and L. R. Faulkner, "Electrochemical Methods, Fundamentals and Applications", 1980, Wiley, New York, 96

46. C. P. Andrieux and J. M. Saveant, J. Electroanal. Chem., 1978, 93, 163.

47. A. J. Bard and L. R. Faulkner, "Electrochemical Methods, Fundamentals and Applications", 1980, Wiley, New York, 288.

48. M. H. Pournaghi-Azar, H. Razmi-Nerbin, and B. Hafezi, Electroanalysis, 2002, 14, 206.

49. F. J. Welcher, "Standard Methods of Chemical Analysis", 6th ed., 1963, New York, 493. 